DOI 10.31509/2658-607x-2019-2-1-1-15

УДК 533.6

ФИЗИЧЕСКОЕ МОДЕЛИРОВАНИЕ ПРОЦЕССОВ ЗАЖИГАНИЯ ЕЛОВОЙ ХВОИ УГЛЕРОДИСТОЙ НАГРЕТОЙ ДО ВЫСОКИХ ТЕМПЕРАТУР ЧАСТИЦЕЙ

\author{
(C) 2019 г. \\ Н.В. Барановский, А.В. Захаревич
}

Наџиональный исследовательский Томский политехнический университет

Россия, 634050 Томск, пр. Ленина, 30

E-mail: firedanger@yandex.ru

Поступила в редакцию 11.03.2019

\begin{abstract}
Лесные пожары возникают в результате природных и антропогенных причин. Известно, что нагретые до высоких температур частицы являются распространенным источником повышенной температуры. Цель работы - физическое моделирование зажигания типичного лесного горючего материала (хвоя ели) нагретой до высоких температур частицей углерода и выявление предельных условий возгорания типичного лесного горючего материала (ЛГМ). Ежегодно натурные наблюдения и сбор образцов лесных горючих материалов для экспериментальных исследований осуществляется в Тимирязевском лесничестве Томской области. Рассматривается типичный лесной горючий материал - еловая хвоя. Источники нагрева при возгорании лесных горючих материалов моделировались изготовленными из графита частицами в форме параллелепипеда с характерными размерами по трем координатным направлениям (14 мм, 8 мм, 8 мм). Вес такой частицы графита составлял 1.3 г. Эксперименты выполнялись в диапазоне изменения начальных температур $T_{0}$ от 1113 К до 1273 К. Численный анализ показывает, что при низкой высоте отделения частица по максимуму сохраняет свое теплосодержание, остывая только в приповерхностных слоях. Первоначально исследован механизм возникновения возгорания в результате действия горящей графитовой частицы. Установлен физический механизм воспламенения слоя лесного горючего материала при выпадении нагретой до высоких температур углеродистой частицы в пламенном и беспламенном режиме. Проведена серия опытов и получена зависимость времени задержки зажигания от начальной температуры частицы. Анализ показал, что зависимость времени задержки зажигания от начальной температуры частицы можно в первом приближении аппроксимировать прямой. Полученные результаты могут быть использованы для разработки и верификации математических моделей зажигания лесных горючих материалов нагретой до высоких температур частицей.
\end{abstract}

Ключевые слова: лесной горючий материал, механизм, физическое моделирование, время задержки зажигания, частища, ель

Лесные пожары возникают в результате природных и антропогенных причин (Hu, Zhou, 2014). Основная природная причина - это воздействие наземного грозового разряда, в результате которого происходит фрагментация древесины (Baranovskiy et al., 2017). В итоге образуются нагретые до высоких температур частицы древесины. Такие частицы могут выпадать на слой лесного горючего материала и приводить к его воспламенению (Suzuki, Manzello, 2019). В результате возникает низовой лесной пожар (Grishin, 1997). Другой сценарий соответствует антропогенному воздействию, когда на лесопокрытой территории остаются непотушенные костры (Янко, 2005). В результате растрескивания древесины в 
костре ее частицы малого размера могут перемещаться на слой лесного горючего материала вблизи костра и приводить к возникновению возгорания. В итоге возможно возникновение низового лесного пожара. Также следует отметить, что образование таких частиц может происходить непосредственно при активных лесных пожарах (Manzello et al., 2006). В последствии такие частицы в результате вертикального и горизонтального переноса могут покидать зону лесного пожара и переносится на расстояние до нескольких сот метров (Теребнев и др., 2007). Затем такие частицы оседают на слой лесного горючего материала и могут приводить к возникновению нового возгорания. Именно так и происходит возникновение пятнистых лесных пожаров (Гришин, 1981).

Для разработки систем прогнозирования лесной пожарной опасности нового поколения необходимо учитывать физико-химические процессы, протекающие при воспламенении слоя лесного горючего материала. Для выявления физического механизма и последующей верификации таких моделей необходимо проведение экспериментов по физическому моделированию процессов зажигания типичных лесных горючих материалов нагретой до высоких температур частицей углерода, которая является широко распространенным источником повышенной температуры.

Цель работы: физическое моделирование зажигания типичного лесного горючего материала (хвоя ели) нагретой до высоких температур частицей углерода и выявление предельных условий возгорания типичного лесного горючего материала.

\section{ОБЛАСТЬ ИССЛЕДОВАНИЯ}

Экологическая система лесов Российской Федерации занимает 1.2 млрд га территории и содержит около 25\% лесных ресурсов всей планеты. Российские леса не только экономический, но и важнейший экологический ресурс, так как РФ обеспечивает ежегодное депонирование углерода в объеме 29 млрд т. Глобальные процессы регулирования состояния окружающей среды, биоразнообразия, климата, речных стоков подвержены значительному влиянию лесов РФ (Кузнецов и др., 2005).

Томская область, в особенности ее северная часть, является типичной территорией бореальной лесной зоны. На ее примере возможно достаточно общее описание условий возникновения пожаров. Область располагает большими лесными ресурсами. Земли лесного фонда занимают 90.5 \% всей ее территории. Древесными породами покрыта площадь в 17 млн га, в том числе 9.9 млн га - хвойными видами (Паневин, 2006). Основными типами рельефа в пределах Томской области являются водораздельные равнины и речные долины наряду с ложбинами древнего стока (Евсеева, Земцов, 1990). Водораздельные равнины представлены положительными и отрицательными морфоструктурами. 
Леса области располагаются в бассейне р. Обь на исключительно равнинной с избыточным увлажнением территории и имеют большое природоохранное значение (Паневин, 2006). Относительно суровые климатические условия определяют достаточно ограниченный породный состав лесов. Наиболее распространенные виды древостоя - сосна обыкновенная, кедр сибирский, ель сибирская, пихта сибирская, береза повислая и пушистая, осина и лиственница сибирская (Паневин, 2006; Горина, 2008).

Пожарная опасность лесов Томской области определяется наличием значительной доли хвойных лесов, развитым горимым напочвенным покровом и жарким сухим летом. Климат Томской области резко-континентальный бореального типа (Горина, 2008). На территориях с континентальным климатом создаются особо благоприятные для возникновения лесных пожаров условия (Курбатский, 1964). В лесах области в зависимости от условий погоды выражены все три пика сезонной горимости: весенняя волна пожаров, летние устойчивые пожары и осенние пожары (Паневин, 2006).

Особенностью лесов Томской области является наличие горючего материала во всех насаждениях. В области развиваются преимущественно низовые пожары (98.5\%), на долю верховых пожаров приходится 1.1\% происшествий и 12.5\% выгоревшей площади, еще реже возникают подземные пожары (Паневин, 2006). Доля пожаров по антропогенным причинам по годам достаточно стабильна, а пожары от грозового разряда носят циклический характер. Периоды с массовыми грозами сменяются более спокойными. Горимость лесов области значительно изменяется и по месяцам пожароопасного сезона. Наиболее «горимые» месяцы июнь и июль. Продолжительность пожароопасного сезона по условиям погоды составляет от 137 до 161 дня (Паневин, 2006). Статистика лесных пожаров по Томской области согласно данным Рослесхоза свидетельствует о том, что примерно 200 лесных пожаров обусловлено воздействием антропогенного фактора и около 75 лесных пожаров возникает в результате воздействия грозовой активности (по данным на 2016 год). Часть пожаров возникает в результате перехода сельскохозяйственных палов на лесопокрытые территории.

Ежегодно натурные наблюдения и сбор образцов лесного горючего материала (далее ЛГМ) для экспериментальных исследований осуществляется в Тимирязевском лесничестве Томской области. Указанное лесничество Томского управления лесами расположено в междуречье двух больших рек (Оби и Томи) на территории трех административных районов Томской области - Томского, Шегарского и Кожевниковского. Протяженность территории лесхоза с Севера на Юг - 64 км, с Запада на Восток - 50 км. Леса лесхоза в основном представлены единым лесным массивом, кроме обособленных припоселковых кедровников населенных пунктов Зоркальцево, Нижне-Сеченово и Губино (Маценко и др., 1999). 
По лесорастительному районированию Западной Сибири территория Тимирязевского лесничества Томской области относится к зоне Южной тайги (Обско-Томского кедровососнового лесорастительного округа). По принятому Томским отделением Сибгипрозема агроклиматическому районированию Томской области территория лесничества отнесена к умеренно-увлажненному району. Продолжительность вегетационного периода составляет 120 дней. Преобладающей породой является сосна - 39.6 \%. Осина составляет $26.2 \%$, береза $21.2 \%$, кедр, лиственница, ель и пихта - 13\% (Маценко и др., 1999). Несколько лет в состав Тимирязевского лесничества входит бывший Калтайский лесхоз как Калтайское участковое лесничество.

\section{МАТЕРИАЛЫ И МЕТОДЫ}

Для физического моделирования зажигания лесного горючего материала использовалась экспериментальная установка и методика, подробно описанные ранее (Захаревич и др., 2008; Кузнецов и др., 2008). Схема экспериментальной установки представлена на рисунке 1.

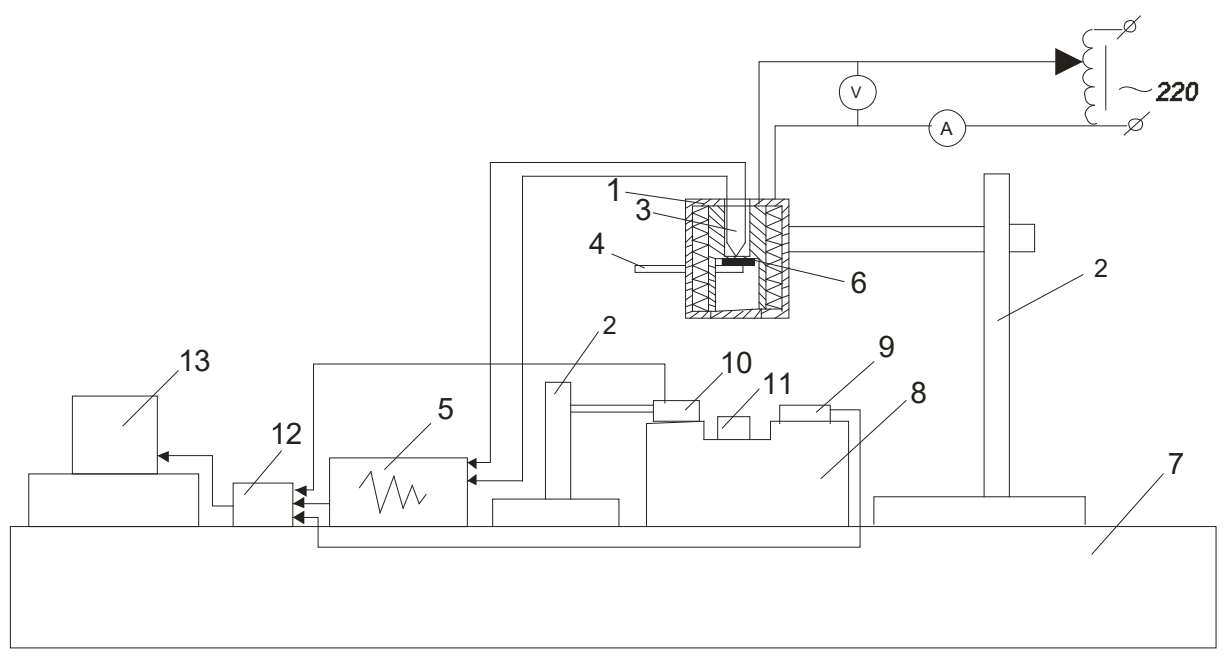

Рисунок 1. Вид экспериментальной установки: 1-нагревательный прибор, 2 - штатив, 3хромель-алюмелевая термопара, 4-керамический стержень, 5 - устройство контроля температуры УКТ38-Щ4-ТП, 6-металлическая частица, 7-рабочая поверхность экспериментальной установки, 8-огнестойкая площадка, 9-приемник излучения и регистратор пламени, 10-излучатель, 11 - вертикальный стеклянный цилиндрический сосуд, 12-аналого-цифровой преобразователь (АЦП), 13- персональный компьютер (Захаревич и др., 2008; Кузнецов и др., 2008)

Источники нагрева при возгорании ЛГМ моделировались изготовленными из графита частицами в форме параллелепипеда с характерными размерами по трем координатным направлениям (14 мм, 8 мм, 8 мм). Вес такой частицы графита составлял 1.3 г. Эксперименты выполнялись в диапазоне изменения начальных температур $T_{0}$ от 1113 К до 1273 К. Этот диапазон был выбран для того, чтобы выделить, во-первых, нижние пределы зажигания 
исследовавшегося ЛГМ по температуре. Верхний предел по температуре выбирался исходя из условий возгорания частицы графита на воздухе (горящая частица всегда при выпадении на слой ЛГМ вызывала его воспламенение). Численный анализ показывает, что при низкой высоте отделения частица по максимуму сохраняет свое теплосодержание, остывая только в приповерхностных слоях. Центральная массивная часть частицы за период осаждения не остывает независимо от высоты отделения. В результате выпадения такой частицы на слой напочвенного лесного горючего материала в месте контакта будет происходить сток тепла в приповерхностные слои лесного горючего материала. В последующие моменты времени может происходить термическое разложение и газофазное воспламенение слоя лесного горючего материала. Как результат, возможно возникновение низового лесного пожара (Grishin et al., 1998; Podur et al., 2003).

Эксперименты проводились по классическому плану с рандомизацией в связи с тем, что до настоящего времени не определена математическая модель, описывающая связь времени задержки зажигания ЛГМ от начальной температуры локального источника нагрева. При постоянном значении $T_{0}$ проводились 5-7 экспериментов, рассчитывалось среднеквадратичное отклонение и доверительные интервалы определения $\mathrm{t}_{\mathrm{gnn}} \mathrm{c}$ доверительной вероятностью $P=0.95$ (Вентцель, 1999). Предполагалось нормальное распределение измеряемой величины (время задержки зажигания). Эксперименты выполнялись с группой идентичных по размерам и условиям изготовления графитовых частиц. Перед опытами проводилась термическая обработка источников нагрева в индукционной печи для «выжигания» летучих соединений. Каждая частица использовалась только в одном эксперименте, потому что ее состояние (форма, размеры, структура приповерхностных слоев) после опыта менялось. Эти изменения в целом были незначительные, но для уменьшения погрешностей проводимых исследований частицы повторно не использовались.

Следует отметить, что процесс зажигания углеродистой частицей отличается от аналогичного процесса со стальной частицей в качестве источника возгорания. Для одиночных углеродистых частиц при высоких температурах характерен процесс газификации, который происходит при интенсивном проникновении газовых реагентов через пористую структуру частицы (Виленский, Хзмалян, 1978; Головина, 1983; Morell et al., 1990). То есть оказываются важными процессы диффузии. Показано что для крупных частиц значительное влияние на процесс газификации оказывают именно диффузионные явления (Самуйлов и др., 2004) и преобразования компонентов внутри частицы, что приводит к изменению самой пористой структуры (Jones et al., 1999). 
Вид глобальной реакции газификации следующий: $\mathrm{C}+\mathrm{CO}_{2} \rightarrow 2 \mathrm{CO}$ (Самуйлов и др., 2004). Согласно (Laurendau, 1978), этот процесс включает цепочку реакций на поверхности пор:

$\mathrm{C}_{\mathrm{f}}+\mathrm{CO}_{2} \leftrightarrow \mathrm{C}(\mathrm{O})_{\mathrm{L}}+\mathrm{CO}$,

$\mathrm{C}(\mathrm{O})_{\mathrm{L}} \rightarrow \mathrm{C}_{\mathrm{f}}+\mathrm{CO}$,

$\mathrm{C}(\mathrm{O})_{\mathrm{L}} \leftrightarrow \mathrm{C}(\mathrm{O})_{\mathrm{S}}$,

$\mathrm{C}(\mathrm{O})_{\mathrm{S}} \rightarrow \mathrm{C}_{\mathrm{f}}+\mathrm{CO}$,

где $\mathrm{C}_{\mathrm{f}}, \mathrm{C}(\mathrm{O})_{\mathrm{L}}, \mathrm{C}(\mathrm{O})_{\mathrm{S}}$ - соответственно свободные активные углеродные центры, атом кислорода, соединенный с атомом углерода подвижной ионной связью, и атом кислорода, образующий неподвижную карбонильную связь с атомом углерода.

К настоящему времени сложились и новые подходы к изучению механизма и закономерностей гетерогенных реакций горения и газификации углерода (Головина, 2002). Если в рамках диффузионно-кинетической теории гетерогенного горения и газификации углерода о закономерностях процесса судили по поведению только газовой фазы, то в настоящее время наряду с газовой учитывают и изменения твердой фазы. Для этого введено понятие активных центров поверхности (ASA) или, шире, реакционно-активных центров (RSA). Реакционно-активная поверхность определяется концентрацией активных углеродных атомов, на которых образуется углеродно-кислородный комплекс, дающий при разложении газообразный продукт (Головина, 2002; Lizzo et al., 1990).

Предварительное помещение их в индукционную печь показало, что в диапазоне температур 1113 - 1273 К графитовая частица горит в пламенном режиме. Выпадение такой частицы на слой ЛГМ также однозначно приводит к возникновению возгорания. Вероятно, первоначальный нагрев графитовой частицы сопровождается выходом каких-либо летучих соединений, которые сгорают в газовой фазе. Последующий нагрев частицы не сопровождается появлением пламени вокруг частицы. Серия предварительных опытов показала, что для углеродистой частицы характерно ее выгорание с течением времени. Это может быть объяснено рассмотренными выше процессами газификации углеродистой частицы, а также гетерогенной реакцией окисления самого углерода.

Объектом исследования были модельные слои типичного ЛГМ (еловая хвоя с веточками), которые формировались в огнеупорной кювете посредством хаотической укладки веточек с хвоинками равномерным слоем.

Характеристики ЛГМ:

а) зеленая хвоя с небольшим серо-бурым оттенком;

б) хвоя и веточки текущего сбора практически не разложившиеся;

в) предварительно высушенный материал; 
г) основную фракцию составляли хвоинки с размером (1.5-2) см в продольном и (0.71.3) мм в поперечном направлении;

д) фракция веточек отличающихся от основной части хвоинок составляла около $25 \%$.

\section{РЕЗУЛЬТАТЫ И ОБСУЖДЕНИЕ}

Установлены следующие закономерности исследуемого процесса. Возможны два варианта реализации условий зажигания.

1) Первоначально исследован механизм возникновения возгорания в результате действия горящей графитовой частицы. Углеродистая частица, сопровождаемая факелом пламени горения летучих соединений, выпадает на слой ЛГМ, который прогревается в результате действия трех механизмов передачи тепла: кондукции, конвекции и излучения (скорее всего конвективный и лучистый перенос являются основными в данном механизме зажигания). Отдельные хвоинки прогреваются и начинают термически разлагаться с выделением газообразных продуктов пиролиза. Происходит вдув газообразных горючих продуктов и зажигание ЛГМ в газовой фазе. Для момента зажигания характерно появление второго факела пламени (первый формируется в результате горения летучих продуктов, выделяемых частицей). Затем происходит объединение факелов и последующее распространение пламени по слою ЛГМ.

б) Далее был исследован механизм зажигания слоя ЛГМ нагретой до высоких температур углеродистой частицей (беспламенный режим) (рис. 2). После начальной стадии непродолжительного периода инертного прогрева слоя ЛГМ начинается термическое разложение материала с выделением газообразных продуктов пиролиза. В зоне контакта хвоинки из гетерогенного слоя ЛГМ разлагаются практически полностью с небольшим коксовым остатком, который выпадает на подложку. Тонкие веточки термически разлагаются в тонком приповерхностном слое. В пористой среде ЛГМ происходит фильтрация газообразных продуктов пиролиза к нагреваемой поверхности слоя и их смешивание с окислителем, нагрев газовой смеси с последующим зажиганием. В большинстве экспериментов факел пламени формировался над нагретой частицей. 


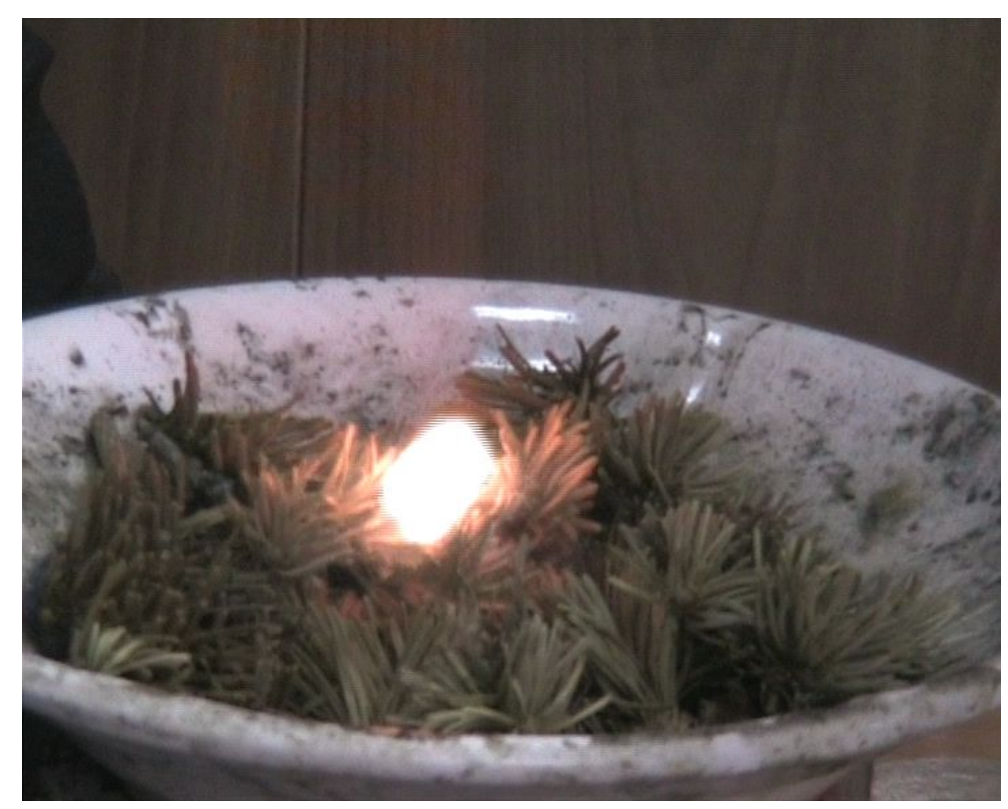

a)

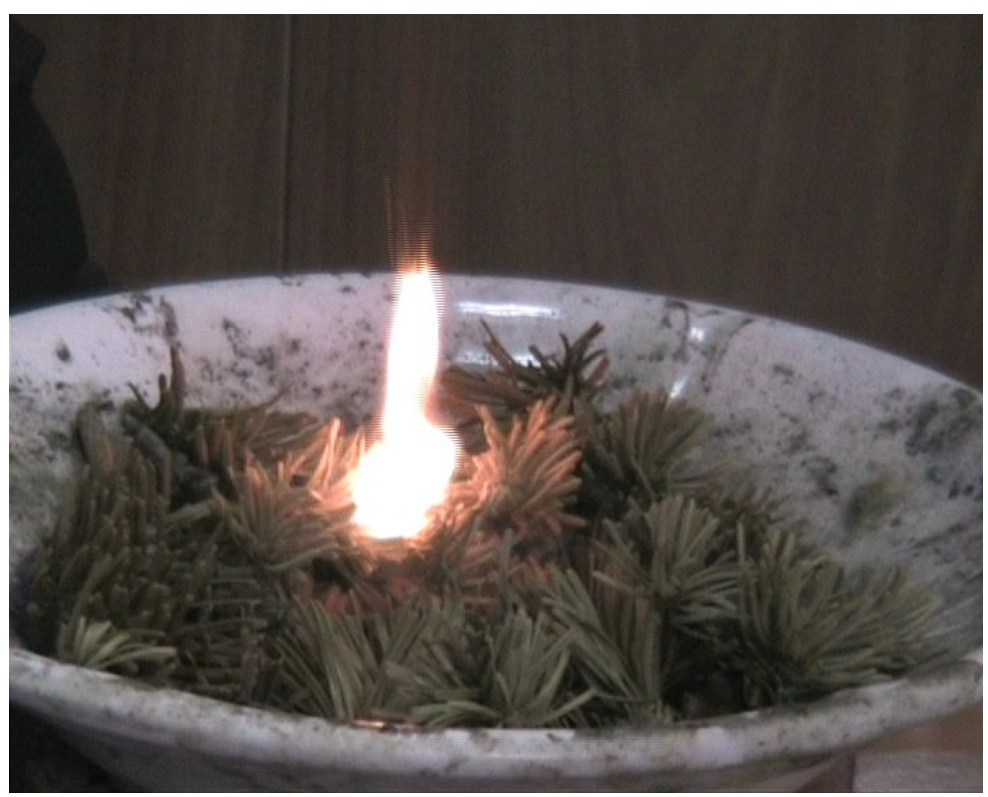

б)

Рисунок 2. Характерные кадры видеосъемки процесса зажигания ЛГМ нагретой до высоких температур частицей в различные моменты времени: a) $\mathrm{t}=0.08 \mathrm{c}$ - инертный прогрев слоя ЛГМ; б) t=0.24 c - появление микрофакела пламени

На рисунке 3 представлена зависимость времени задержки зажигания от начальной температуры частицы с указанием доверительных интервалов. Выделен нижний предел зажигания по температуре. В отличие от опада сосны исследуемый образец характеризовался упорядоченным распределением отдельных хвоинок, тонких веточек и зачастую фиксированным расстоянием между ними. Структура образца характеризовалась пористостью, обусловленной упорядоченной структурой хвоинок, а также крупным поровым 
пространством, обусловленным морфологией еловых веточек, что привело к достаточно высоким значения среднеквадратичных отклонений результатов измерений $\mathrm{t}_{\mathrm{ggn}}$ от средних значений. За счет этого в каждом конкретном эксперименте из серии опытов при идентичной начальной температуре отличались и условия теплообмена между источником возгорания и слоем ЛГМ.

Анализ рисунка 3 показывает, что зависимость времени задержки зажигания от начальной температуры частицы можно в первом приближении аппроксимировать прямой. Однако более качественно полученные экспериментальные данные описывает параболическая зависимость. Ранее подобный факт был установлен при исследовании процессов воспламенения травяной ветоши с плотностью укладки, соответствующей природным условиям. Однако, дальнейшее ее увеличение привело к линейной зависимости времени задержки зажигания от начальной температуры нагретой частицы. Отличие от линейной зависимости было обусловлено, вероятно, неидентичностью процессов тепломассопереноса в сложном структурно неоднородном материале. Это же, вероятно, служит причиной отклонения от линейной зависимости и в случае с исследованием еловых веточек с хвоей.

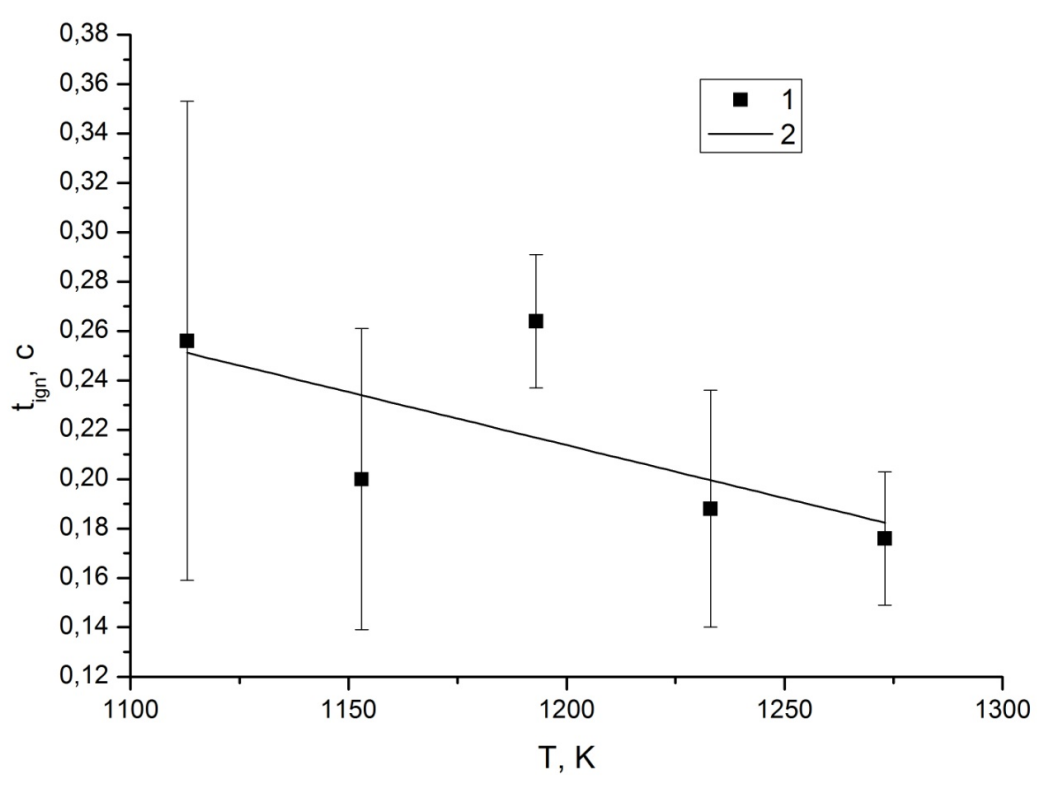

Рисунок 3. Зависимости времени задержки зажигания ЛГМ от начальной температуры частицы: 1, 2- усредненные значения и аппроксимирующая прямая (частица $\mathrm{h}=14 \mathrm{mM} ; \mathrm{x}_{1}=8$ мм; $\mathrm{x}_{2}=8 \mathrm{мM} ; \mathrm{m}=1.3$ г)

Следует отметить, что выполненные экспериментальные исследования показали высокую устойчивость процесса зажигания слоя ЛГМ с разномасштабной пористостью одиночной нагретой до высоких температур углеродистой частицей. Развитие процесса зажигания достаточно хорошо демонстрирует типичная видеограмма опыта. 
Следует особо отметить, что экспериментальные значения $t_{\text {ign }}$ (рис. 3) при $T_{0}=1273 \mathrm{~K}$ можно сравнить со значениями времени задержки воспламенения типичного жидкого топлива - керосина в адекватных условиях теплового воздействия (Захаревич, 2008). $t_{\text {ign }}$ керосина более чем в два раза превышает аналогичное значение для опада хвойных пород деревьев. При этом нижние предельные значения температур зажигания керосина почти на 100 К превышают представленные на рис. 3. Установленное по результатам экспериментов соотношение между характерными временами зажигания опада хвойных деревьев и типичного жидкого топлива обусловлено особенностями тепломассопереноса в прогретом слое и на поверхности этих горючих веществ при локальном тепловом воздействии. Так, например, результаты исследований (Кузнецов, Стрижак, 2008, 2009; Kuznetsov, Strizhak, 2009) показывают, что при нагреве как пленок, так и больших масс жидких топлив, значительная часть подводимой тепловой энергии расходуется на энергоемкий процесс образования паров горючего. Теплота фазового перехода - испарения любого жидкого топлива существенно (более чем в 10 раз) выше теплоты, затрачиваемой на газификацию лесного горючего материала (термическое разложение). Соответственно необходим более длительный прогрев жидкого топлива по сравнению с ЛГМ для инициирования химической реакции горения.

\section{ЗАКЛЮЧЕНИЕ}

Проведены дополнительные эксперименты с типичным ЛГМ Томской области (веточки ели, покрытые хвоей), которые показали необходимость дальнейшего усовершенствования математических моделей зажигания ЛГМ локальным источником нагрева. Анализ результатов показывает, что для образцов ЛГМ с крупными поровыми пространствами линейная зависимость времени задержки зажигания от начальной температуры нагретой частицы применима лишь в первом приближении. На следующем этапе следует разработать усовершенствованную математическую модель зажигания ЛГМ с учетом мелких и крупных пор в слое ЛГМ.

\section{БЛАГОДАРНОСТИ}

Исследование выполнено при поддержке Российского фонда фундаментальных исследований и администрации Томской области. Научный проект № 16-41-700831.

\section{СПИСОК ЛИТЕРАТУРЫ}

Вентцель Е.С. Теория вероятностей. М.: Высш. шк., 1999. 576 С.

Виленский Т.В., Хзмалян Д.М. Динамика горения пылевидного топлива. М.: Энергия, 1978. C. 
Головина E.C. Высокотемпературное горение и газификация углерода. М.: Энергоатомиздат, 1983.

Головина E.C. Исследование гетерогенного горения и газификации углерода и твердого топлива (Обзор) // Физика горения и взрыва. 2002. Т. 38. № 4. С. 25-34.

Горина Н.В. Лесные пожары // Безопасность жизнедеятельности. 2008. № 1. С. 57-60.

Гришин А.М. Математические модели лесных пожаров. Томск: Изд-во Томского университета, 1981. 278 C.

Евсеева И.С., Земцьов А.А. Рельефообразование в лесоболотной зоне ЗападноСибирской равнины. Томск: Изд-во Том. ун-та, 1990. 242 с.

Захаревич A.B. Зажигание твердых и жидких конденсированных веществ одиночными нагретыми до высоких температур частицами. Дис. ... канд. физ.-мат. наук. Томск: ТПУ, 2008. $117 \mathrm{c}$.

Захаревич А.В., Кузнецов В.Т., Кузнещов Г.В., Максимов В.И. Зажигание модельных смесевых топливных композиций одиночной нагретой до высоких температур частицей // Физика горения и взрыва. 2008. Т. 44. № 5. С. 54 - 57.

Кузнецов Г.В., Захаревич А.В., Максимов В.И. Зажигание дизельного топлива одиночной “горячей” металлической частицей // Пожаровзрывобезопасность. 2008. Т. 17. № 4. C. $28-30$.

Кузнецов Г.В., Стрижак П.А. Нагретые до высоких температур частицы металла как источники локальных возгораний жидких веществ // Пожарная безопасность. 2008. № 4. С. 72 $-76$.

Кузнецов Г.В., Стрижак П.А. Моделирование воспламенения жидкого вещества горячей частицей // Химическая физика. 2009. Т. 28. № 5. С. 91-98.

Кузнецов В.И., Козлов Н.И., Хомяков П.М. Математическое моделирование эволюции леса для целей управления лесным хозяйством. М.: ЛЕНАНД, 2005. 232 с.

Курбатский Н.П. Пожары тайги, закономерности их возникновения и развития: Автореф. дис. ... доктора с.-х. наук / ИЛиД СО АН СССР. Красноярск, 1964. 38 с.

Маценко В.В., Соколов А.Я., Калинин С.И. Генеральный план противопожарного устройства лесов. Т. 1. Пояснительная записка. 5-99.14-17-ПМ / Государственный проектноизыскательский институт «Росгипролес», Алтайский филиал. Барнаул, 1999. 139 с.

Паневин В.С. Леса и лесное хозяйство Томской области: учеб. пособие. Томск: Изд-во Том. ун-та, 2006. 126 C.

Самуйлов Е.В., Фаминская М.В., Головина Е.С. Модель и расчет процесса газификации одиночной углеродной частицы // Физика горения и взрыва. 2004. Т. 40. № 1. С. 86-94. 
Теребнев В.В., Артемьев Н.С., Подгрушный А.В. Противопожарная защита и тушение пожаров. Книга 5. Леса, торфяники, лесосклады. М.: Изд-во "Пожнаука", 2007. 358 с.

Янко И.В. Пирологическая оценка территории Томской области. Дисс. ... канд. геогр. наук. Томск: Томский государственный педагогический университет, 2005. 174 с.

Baranovskiy N.V., Kuznetsov G.V., Nemova T.N. High temperature wood particles formation caused by the cloud-to-ground lightning discharge through the coniferous tree trunk // Far East Journal of Mathematical Sciences. 2017. Vol. 102. P. 1033-1044.

Grishin A.M. Mathematical modeling of forest fire and new methods of fighting them. Russia. Tomsk: Publishing House of the Tomsk State University, 1997. 390 P.

Grishin A.M., Dolgov A.A., Zima V.P., Kryuchkov D.A., Reino V.V., Subbotin A.N., Tsvyk R.Sh. Ignition of a layer of combustible forest materials // Combustion, Explosion and Shock Waves. 1998. Vol. 34. P. 613-620.

Hи T., Zhou G. Drivers of lightning- and human-caused fire regimes in the Great Xing'an Mountains // Forest Ecology and Management. 2014. Vol. 329. P. 49-58.

Jones J.M., Pourkashanian M., Rena C.D., Williams A. Modelling the relationship of coal structure to chair porosity // Fuel. 1999. Vol. 78. P. 1737-1744.

Kuznetsov G.V., Strizhak P.A. 3D Problem of heat and mass transfer at the ignition of a combustible liquid by a heated metal particle // Journal of Engineering Thermophysics. 2009. Vol. 18. N 1. P. 72-79.

Laurendau N.M. Heterogeneous kinetics of coal char gasification and combustion // Prog. Energy and Combust. Sci. 1978. Vol. 4. N 4. P. 221-270.

Lizzo A., Hong Jiang, Radovic R. On the kinetics of carbon (char) gasification: reconciling model with experiments // Carbon. 1990. Vol. 28. No 1. P. 7-19.

Manzello S.L., Cleary T.G., Shields J.R., Yang J.C. Ignition of mulch and grasses by firebrands in wildland-urban interface fires // International Journal of Wildland Fire. 2006. Vol. 15. P. 427-431.

Morell J.I., Amundson N.R., Park S.K. Dynamics of a single particle during char gasification // Chem. Eng. Sci. 1990. Vol. 45. No 2. P. 387-401.

Podur J., Martell D. L., Csilagg F. Spatial patterns lightning-caused forest fires in Ontario 1976-1998 // Ecological Modelling. 2003. Vol. 164. No 1. P. 1-20.

Suzuki S., Manzello S.L. Investigating effect of wind speeds on structural firebrand generation in laboratory scale experiments // International Journal of Heat and Mass Transfer. 2019. Vol. 130. P. 135-140. 


\section{REFERENCES}

Baranovskiy N.V., Kuznetsov G.V., Nemova T.N., High temperature wood particles formation caused by the cloud-to-ground lightning discharge through the coniferous tree trunk, Far East Journal of Mathematical Sciences, 2017, Vol. 102, pp. 1033-1044.

Evseeva I.S., Zemtsov A.A., Rel'yefoobrazovaniye v lesobolotnoy zone Zapadno-Sibirskoy ravniny (Relief formation in the forest-swamp zone of the Zapadno-Siberian plain), Tomsk: Publishing house Tom. University, 1990, 242 p.

Golovina E.S., Vysokotemperaturnoye goreniye i gazifikatsiya ugleroda (High-temperature combustion and gasification of carbon), Moscow: Energoatomizdat, 1983.

Golovina E.S., Issledovaniye geterogennogo goreniya i gazifikatsii ugleroda i tverdogo topliva (Obzor) (Study of Heterogeneous Combustion and Gasification of Carbon and Solid Fuel (Review), Fizika goreniya i vzryva, 2002, Vol. 38, No. 4, pp. 25-34.

Gorina N.V., Lesnyye pozhary (Forest Fires), Bezopasnost' zhiznedeyatel'nosti, 2008, No. 1, pp. $57-60$.

Grishin A.M., Matematicheskiye modeli lesnykh pozharov (Mathematical models of forest fires), Tomsk: Tomsk University Press, 1981, 278 p.

Grishin A.M., Mathematical modeling of forest fire and new methods of fighting them. Russia. Tomsk: Publishing House of the Tomsk State University, 1997, 3903.

Grishin A.M., Dolgov A.A., Zima V.P., Kryuchkov D.A., Reino V.V., Subbotin A.N., Tsvyk R.Sh., Ignition of a layer of combustible forest materials, Combustion, Explosion and Shock Waves, 1998, Vol. 34, pp. 613-620.

Hu T., Zhou G. Drivers of lightning- and human-caused fire regimes in the Great Xing'an Mountains, Forest Ecology and Management, 2014, Vol. 329, pp. 49-58.

Jones J.M., Pourkashanian M., Rena C.D., Williams A., Modelling the relationship of coal structure to chair porosity, Fuel, 1999, Vol. 78, pp. 1737-1744.

Kuznetsov G.V., Zakharevich A.V., Maksimov V.I., Zazhiganiye dizel'nogo topliva odinochnoy "goryachey" metallicheskoy chastitsey (Ignition of diesel fuel by a single "hot" metal particle), Pozharovzryvobezopasnost', 2008. Vol. 17, No. 4, pp. 28-30.

Kuznetsov G.V., Strizhak P.A., Nagretyye do vysokikh temperatur chastitsy metalla kak istochniki lokal'nykh vozgoraniy zhidkikh veshchestv (Metal particles heated to high temperatures as sources of local ignitions of liquid substances), Pozharnaya bezopasnost', 2008, No. 4. pp. 72-76.

Kuznetsov G.V., Strizhak P.A., Modelirovaniye vosplameneniya zhidkogo veshchestva goryachey chastitsey (Simulation of the ignition of a liquid substance by a hot particle), Khimicheskaya fizika, 2009, Vol. 28, No. 5, pp. 91-98. 
Kuznetsov G.V., Strizhak P.A., 3D Problem of heat and mass transfer at the ignition of a combustible liquid by a heated metal particle, Journal of Engineering Thermophysics, 2009, Vol. 18, No 1, pp. 72-79.

Kuznetsov V.I., Kozlov N.I., Khomyakov P.M., Matematicheskoye modelirovaniye evolyutsii lesa dlya tseley upravleniya lesnym khozyaystvom (Mathematical modeling of forest evolution for forest management purposes), Moscow: LENAND, 2005. 232 p.

Kurbatskiy N.P. Pozhary taygi, zakonomernosti ikh vozniknoveniya i razvitiya (The Fires of the Taiga, the Patterns of Their Origin and Development): Author's abstract. diss. ... doctor agricultural sciences / ILID SO of the USSR. Krasnoyarsk, 1964. 38 p.

Laurendau N.M., Heterogeneous kinetics of coal char gasification and combustion, Prog. Energy and Combust. Sci., 1978, Vol. 4, No 4., pp. 221-270.

Lizzo A., Hong J., Radovic R., On the kinetics of carbon (char) gasification: reconciling model with experiments, Carbon, 1990, Vol. 28, No 1., pp. 7-19.

Matsenko V.V., Sokolov A.Ya., Kalinin S.I., General'nyy plan protivopozharnogo ustroystva lesov (Master Plan for Fire Protection Plants), Vol. 1., Explanatory note, 5-99.14-17-PM / State Design and Survey Institute "Rosgiproles", Altai branch. Barnaul, 1999, 139 p.

Manzello S.L., Cleary T.G., Shields J.R., Yang J.C., Ignition of mulch and grasses by firebrands in wildland-urban interface fires, International Journal of Wildland Fire, 2006, Vol. 15, pp. 427-431.

Morell J.I., Amundson N.R., Park S.K., Dynamics of a single particle during char gasification, Chem. Eng. Sci. 1990, Vol. 45, No 2, pp. 387-401.

Panevin V.S., Lesa i lesnoye khozyaystvo Tomskoy oblasti (Forests and Forestry of the Tomsk Region), Tomsk: Publishing house Tom. University, 2006, 126 p.

Podur J., Martell D. L., Csilagg F., Spatial patterns lightning-caused forest fires in Ontario 1976-1998, Ecological Modelling, 2003, Vol. 164, No 1, pp. 1-20.

Samuilov E.V., Faminskaya M.V., Golovina E.S., Model' i raschet protsessa gazifikatsii odinochnoy uglerodnoy chastitsy (Model and calculation of the process of gasification of a single carbon particle), Fizika goreniya i vzryva, 2004, Vol. 40, № 1. pp. 86-94.

Suzuki S., Manzello S.L., Investigating effect of wind speeds on structural firebrand generation in laboratory scale experiments, International Journal of Heat and Mass Transfer, 2019, Vol. 130, pp. 135-140.

Terebnev V.V., Artemyev N.S., Podgrushny A.V., Protivopozharnaya zashchita i tusheniye pozharov. Kniga 5. Lesa, torfyaniki, lesosklady, (Fire protection and extinguishing fires. Book 5. Forests, peatlands, forest stands), Moscow: Publishing house "Pozhnauka", 2007. 358 p.

Ventsel E.S., Teoriya veroyatnostey (Probability theory), Moscow: High school, 1999. 576 p. 
Vilenskiy T.V., Khzmalyan D.M., Dinamika goreniya pylevidnogo topliva (The dynamics of the combustion of pulverized fuel), Moscow: Energy, 1978. p.

Yanko I.V., Pirologicheskaya otsenka territorii Tomskoy oblasti (Pyrological assessment of the territory of the Tomsk region). Diss. cand. geogr. sciences. Tomsk: Tomsk State Pedagogical University, 2005, $174 \mathrm{p}$.

Zakharevich A.V., Zazhiganiye tverdykh $i$ zhidkikh kondensirovannykh veshchestv odinochnymi nagretymi do vysokikh temperatur chastitsami (Ignition of solid and liquid condensed substances by single particles heated to high temperatures), Diss. cand. phys.-mat. sciences, Tomsk: TPU, 2008, 117 p.

Zakharevich A.V., Kuznetsov V.T., Kuznetsov G.V., Maksimov V.I., Zazhiganiye model'nykh smesevykh toplivnykh kompozitsiy odinochnoy nagretoy do vysokikh temperatur chastitsey (Ignition of Model Mixed Fuel Compositions of a Single Particle Heated to High Temperatures), Fizika goreniya i vzryva, 2008, Vol. 44, No 5, pp. 54-57.

\title{
EXPERIMENTAL MODELLING OF SPRUCE NEEDLES IGNITION BY THE CARBONACEOUS HEATED UP TO HIGH TEMPERATURES PARTICLE
}

\author{
N.V. Baranovskiy, A.V. Zakharevich \\ Tomsk Polytechnic University \\ Lenin av., 30, Tomsk, 634050, Russia \\ E-mail: firedanger@yandex.ru \\ Received 11 March 2019
}

Forest fires occur as a result of natural and man-made causes. It is known that particles heated to high temperatures are a common source of high temperature. The purpose of the work is the physical simulation of the typical forest fuel ignition (spruce needles ignition) by the carbon particle heated to high temperatures and the identification of the typical forest fuel ignition conditions. Every year, field observations and collection of forest fuel samples for experimental studies are carried out in Timiryazevskiy forestry of Tomsk Region. A typical forest fuel (spruce needles) is considered. The sources of heating during the ignition of forest fuel were simulated by the particles made of graphite in the shape of a parallelepiped with characteristic dimensions in three coordinate directions (14 $\mathrm{mm}$, $8 \mathrm{~mm}, 8 \mathrm{~mm}$ ). The weight of such a graphite particle was $1.3 \mathrm{~g}$. Experiments were performed in the range of changes in initial temperatures $T_{0}$ from $1113 \mathrm{~K}$ to $1273 \mathrm{~K}$. Numerical analysis shows that at a low sedimentation height, the particle retains its heat content to the maximum, cooling only in the near-surface layers. Initially, the mechanism of ignition as a result of the action of a burning graphite particle was investigated. The physical mechanism of the forest fuel layer ignition is established when a carbon particle heated to high temperatures falls out in a flameless mode. A series of experiments was carried out and the dependence of the ignition delay on the initial temperature of the particle was obtained. The analysis showed that the dependence of the ignition delay on the initial temperature of a particle can be approximated to a first approximation by a straight line. The obtained results can be used for the development and verification of mathematical models to simulate ignition of forest fuel by the particle heated to high temperatures.

Key words: forest fuel, mechanism, experimental modelling, ignition delay, particle, spruce Рецензент: к.т.н. доцент Гоман П.Н. 